\title{
Família, trabalho com famílias e Serviço Social ${ }^{1}$
}

\section{Regina Célia Mioto*}

A incorporação da família como referência na política social brasileira reavivou o debate em torno do trabalho com famílias, que por muito tempo ficou relegado a segundo plano no âmbito do Serviço Social brasileiro. A secundarizaçao desses temasfamília e trabalho com famílias- tem sido atribuída, por um lado, às exigencias teóricometodológicas impostas para a consolidação da profissão nos marcos da teoría social crítica e, por outro, pela pecha de conservadorismo que marcaram essas temáticas no pós reconceituação. Por isso, impõe-se nesse momento o grande desafio de demarcar tanto o foco de estudo sobre familia que interessa ao campo do Serviço Social - enquanto profissão e área de conhecimento -, como a construção do debate em torno do trabalho com famílias ancorado nas premissas teórico-metodológicas da teoría social social crítica.

$\mathrm{Na}$ tentativa de enfrentar esse desafio e se possível lançar alguma luz sobre a temática, esta apresentação se divide em três partes. Na primeira realiza-se uma breve contextualização da família como objeto de estudo e intervenção do Serviço Social. $\mathrm{Na}$ segunda busca-se demarcar algumas requisições para a orientação do trabalho com famílias e finalmente, na terceira apresenta-se a indicação de algumas pistas para o desenvolvimento do trabalho com famílias.

\section{Breve contextualização}

A família é um sujeito privilegiado de intervenção do Serviço Social desde os primórdios da profissão. No Brasil ele nasce vinculado aos movimentos de ação social numa proposta de dinamização da missão política de apostolado social junto as classes subalternas, particularmente junto a família operária. Ou seja, o alvo predominante do

\footnotetext{
${ }^{1}$ Palestra proferida na Universidade Estadual de Londrina (UEL). Contém idéias e trechos de artigos já publicados em livros e revistas.

*Universidade Federal de Santa Catarina mioto@cse.ufsc.br
} 
exercício profissional é o trabalhador e a sua família, em todos os espaços ocupacionais. (IAMAMOTO, 1983).

A partir de então, pode-se observar que o trabalho com famílias ganhou grande impulso e maior qualificação técnica no período de consolidação da profissão, através da apropriação do marco conceitual do Serviço Social americano, particularmente do Método do Serviço Social de Caso. De acordo com Nicholds (1969), esse método tinha como objetivo realizar o ajustamento dos indivíduos a seu meio, cooperando com eles a fim de beneficiá-los e também a sociedade em geral. Enquanto "método de tratamento" incluía a necessidade de diminuir ou resolver o problema trazido pelos "clientes" e, se possível, modificar as dificuldades e complicações fundamentais.. A assistência ao cliente tinha como premissa a busca de recursos tanto na personalidade como no ambiente para corrigir a situação (HAMILTON, 1976; NICHOLDS, 1969).

Essa postulação sobre o estudo social de caso traz implícita a idéia que as relações sociais dos indivíduos eram compreendidas no plano do imediato e a solução dos problemas sociais como responsabilidade dos próprios indivíduos, leia-se das próprias famílias. Nessa perspectiva o acesso a determinados auxílios materiais e a serviços no âmbito das instituições era realizado após uma série de avaliações e posteriores exigências de mudanças relativas aos modos de vida das famílias. Assim os estudos sociais se vinculavam muito mais a julgamentos morais do assistente social, do que sobre as próprias condições objetivas de vida das famílias. Tudo isso pautado na lógica que o auxílio público só deve acontecer de forma temporária, depois de esgotadas as possibilidades da utilização dos recursos próprios do ambiente (materiais e imateriais). Tal perspectiva revela a franca orientação positivista/funcionalista presente nos processos de abordagem das famílias como foi destacada por inúmeros estudos, como os de Yazbek (1993) e lamamoto (1994). Sob essa orientação os assistentes sociais aprimoraram os seus instrumentos e técnicas direcionados para o processo de averiguação e controle dos modos de vida das famílias, especialmente através de um forte processo de burocratização dos procedimentos e de regulamentação para a condução do atendimento às famílias.

Essa perspectiva seguiu hegemônica no Serviço Social, até que autores e profissionais passaram a discutir a profissão dentro das bases da teoria social de Marx. 
Esta permitiu tanto o avanço do debate teórico-metodológico da profissão quanto à construção de seu projeto ético-político. Esse novo paradigma operou, no contexto do Serviço Social, duas mudanças fundamentais para instituir uma nova forma de pensar e trabalhar a família. Uma refere-se a nova possibilidade de interpretação da demanda. Ou seja, as necessidades trazidas por sujeitos singulares não são mais compreendidas como problemas individuais/familiares. Ao contrário, tais demandas são interpretadas como expressões de necessidades humanas não satisfeitas, decorrentes da desigualdade social própria da organização capitalista. Assim, torna-se possível desvincular-se da idéia que a s necessidades expressas nas famílias e pelas famílias são "casos de família" e, por conseguinte, as questões que afligem as famílias não se circunscrevem no campo da competência ou incompetência desses sujeitos. A outra mudança decorrente da nova perspectiva teórica refere-se ao redimensionamento exigido em relação a ação profissional, tanto no que diz respeito ao seu alcance como a sua direcionalidade. Com a possibilidade de postular que as soluções dos problemas expressos na família e pela família, só se efetivam, de fato, com a transformação das bases de produção e reprodução das relações sociais - superação do modo de produção capitalista - exige-se que a ação profissional seja pensada na sua teleologia. Ou seja, como propõe Guerra (2000) uma ação profissional que se projeta para além de sua eficiência operativa ou de sua instrumentalidade e seja comprometida eticamente com a transformação social. Nesse movimento e reconhecendo o terreno sócio-histórico sobre o qual a profissão se movimenta a categoria dos Direitos e da Cidadania passa a mediar o encaminhamento das ações profissionais. Os direitos, entendidos como caminhos para a concretização da cidadania por meio de políticas sociais orientadas para o atendimento das necessidades humanas, e o Estado reconhecido como instância responsável por essa garantia e atenção (VIEIRA, 2004; LIMA, 2006).

A adoção da matriz da teoria social crítica pelo Serviço proporcionou um amplo desenvolvimento para o Serviço Social brasileiro Nesse percurso, localizado entre os anos de 1970- 2000, destaca-se o reconhecimento do Serviço Social como área de conhecimento, o avanço extraordinário no debate de seus fundamentos, o debate teórico e a inserção política no campo da política social. Porém nesse novo contexto, a família não alcançou o estatuto de objeto de estudo privilegiado no âmbito da profissão e isso 
trouxe conseqüências bastante indesejadas. O fato da família e das formas de intervenção com famílias não ser problematizada e trabalhada dentro do novo marco teórico afetou profundamente o campo da prática profissional. Afinal, as instituições públicas ou não, continuaram sendo o grande campo de trabalho para os assistentes sociais e nelas as famílias continuaram como sujeitos privilegiados de intervenção. Nesse período de efervescência do debate da teoria social crítica, nas palavras de Costa (apud GOULART, 1996) a família é vista "como um desvio de energias e de conhecimentos que poderiam ser canalizados para setores dotados de maior capacidade de respostas em termos de transformação das relações sociais em seu conjunto".

Nesse descompasso passamos a assistir uma "migração" dos assistentes sociais para a busca de referências teóricas alheias às novas referências teórico-metodológicas da profissão. Desde o final dos anos de 1970 e ao longo da década de 1980, houve uma grande incorporação da chamada Terapia Familiar de orientação sistêmica ${ }^{2}$ na prática dos asistentes sociais brasileiros, particularmente aqueles vinculados a área da saúde mental. Um levantamento sobre as publicações sobre família na revista Serviço Social e Sociedade, na década de 1980 , permite observar que os artigos alí publicados revelam duas grandes tendências. Aqueles que buscam vincular a família às condições estruturais da sociedade, colocando a questão das politicas sociais, como os artigos de Seno Cornely e de Cecilia Toron. Outros que se alinham ao tratamento da prática profissional e para tanto se utilizam da orientação sistêmica, como os artigos de Ana Maria Nunes, Maria Amalia Vitalle e Beatriz Sodré.

Nos anos de 1990 a questão da família no Serviço Social vai ter pouca visibilidade se comparada a produção sobre política social e direitos sociais, mas vai sendo anunciada a sua pertinência. Não por acaso, no CBASS de 1998 ela é incorporada como um dos eixos temáticos do Congresso. Finalmente, nos anos 2000 o tema da família vai "tomar de assalto" o Serviço Social. Justamente quando a política social brasileira- no contexto da reforma do Estado brasileiro, induzida pelos ventos da ideología neoliberal - passa a se estruturar dentro da proposta do pluralismo de bem-estar social ${ }^{3}$, enfatizando amplamente a família.

\footnotetext{
${ }^{2}$ A terapia familiar de orientação sistêmica

${ }^{3}$ Sobre pluralismo de bem-estar consultar Pereira (2004)
} 
Nesse momento se explicitam todas as contradições. Ao mesmo tempo em que o Serviço Social se constitui numa área de conhecimento bastante forte em seus fundamentos teórico-metodológicos e ético-políticos e no campo da política social, apresenta-se bastante frágil em relação ao debate sobre a temática da família e da intervenção profissional, particularmente sobre o "como fazer" ${ }^{4}$. Nos termos de Campos (2008,p.114) é "da condição de a metodología não ser outra coisa senão a forma, internamente coerente, refletida, como os nossos fundamentos - pretensões teóricas e metodológias- são colocadas em prática". É, justamente isso que tem reclamado repostas urgentes 5 .

Diante dessa breve contextualização é que passamos a discutir quais as requisições para o trabalho do assistente social com famílias.

\section{Requisições para o trabalho com família}

Como requisições básicas para o trabalho com famílias estamos considerando, nesse momento, a delimitação de determinada concepção de família e de suas relações com a proteção social pautadas nos fundamentos teórico-metodológicos da vertente crítico-dialética para se desdobrar numa prática profissional com suficiente "consistência interna" ${ }^{6}$ guiada pelos princípios ético-políticos do código de ética dos assistentes sociais.

\section{Concepção de família}

A família, nas suas mais diversas configurações constitui-se como um espaço altamente complexo. É construída e reconstruída histórica e cotidianamente, através das relações e negociações que estabelece entre seus membros, entre seus membros e outras esferas da sociedade e entre ela e outras esferas da sociedade, tais como Estado,

\footnotetext{
${ }^{4} \mathrm{O}$ "como fazer" entendido como expressão da apropriação dos fundamentos teórico-metodológicos e ético-políticos do Serviço Social.

5 - Nesse sentido deve ser destacado os esforços empreendidos nesse momento pelo CFESS e pela ABEPSS na discussão sobre a prática profissional.

${ }^{6}$ Para Campos $(2008,117)$, a consistência interna das metodologias de trabalho profissional exigem: "a) seu teste operativo, configurado na capacidade traduzir em atos e posturas os conceitos e objetivos que postula. b) sua resposta definida, adaptada ao tempo e ao espaço em que se desenvolve, condicionantes de sua configuração. c) sua precisão quanto aqueles que busca atingir e à participação deles no desenvolvimento do caminho metodológico. d) sua previsão de recursos de todas as ordens, existentes e disponíveis em determinados prazos; incluem-se aí as pessoas que desenvolvem ações pautadas numa metodologia. e) seu sistema de controle das informações, monitoramento e avaliação."
} 
trabalho e mercado ${ }^{7}$. Reconhece-se também que além de sua capacidade de produção de subjetividades, ela também é uma unidade de cuidado e de redistribuição interna de recursos.

Portanto, ela não é apenas uma construção privada, mas também pública e tem um papel importante na estruturação da sociedade em seus aspectos sociais, políticos e econômicos. E, nesse contexto, pode-se dizer que é a família que "cobre as insuficiências das políticas públicas, ou seja, longe de ser um "refúgio num mundo sem coração" é atravessada pela questão social". (MIOTO, CAMPOS, LIMA, 2004).

Essa concepção, portanto, contrapõe-se àquelas concepções que:

- tratam a família a partir de uma determinada estrutura, tomada como ideal (casal com seus filhos) e com papéis pré-definidos;

- concebem a família apenas numa perspectiva relacional. Ou seja, que as relações familiares estão circunscritas apenas às relações estabelecidas na família, seja no âmbito de seu domicílio, seja na sua rede social primária;

- analisam a família somente a partir de sua estrutura relacional, não incorporando como as relações estabelecidas com outras esferas da sociedade. Por exemplo, como a relação com o Estado, através de sua legislação, de suas políticas econômicas e sociais, interfere na história das famílias, na construção dos processos familiares que são expressos através das dinâmicas familiares.

Consequentemente, se contrapõe às concepções que tomam a família como a principal responsável pelo bem-estar de seus membros, desconsiderando em grande medida às mudanças ocorridas na sociedade. Dentre as mudanças que merecem destaque estão as de caráter econômico, relacionadas ao mundo do trabalho e as de caráter tecnológico, particularmente àquelas vinculadas ao campo da reprodução humana e da informação. Além, sem dúvida, das novas configurações demográficas, que incluem famílias menores, famílias com mais idosos e também das novas formas de sociabilidade desenhadas no interior da família. Uma sociabilidade marcada pelo aumento da tensão entre os processos de individuação e pertencimento. Tais indicadores

\footnotetext{
${ }^{7}$ É importante destacar que as negociações não se fazem entre sujeitos iguais, uma vez que a desigualdade grassa tanto no interior da família, como na relação dela com outras esferas da sociedade. Estas desigualdades estão vinculadas a três eixos fundamentais que são: classe, gênero e etnia.
} 
sinalizam que a família não tem condições objetivas de arcar com as exigências que estão sendo colocadas sobre ela na sociedade contemporânea, especialmente nos países como o Brasil que é marcado por uma desigualdade estrutural.

Dessas afirmações decorre uma questão fundamental para o Serviço Social, que é a demarcação do foco de interesse quando se pensa a questão da família. Nesse sentido, considerando que o objeto de trabalho dos assistentes sociais são as expressões da questão social e que as ações destes profissionais incidem diretamente na construção da proteção social na perspectiva dos Direitos, obviamente o foco de interesse central do Serviço Social é a relação família e proteção social.

\section{Família e proteção social}

Pensar a família no campo da proteção social implica reconhecer que a família na sua dimensão simbólica, na sua multiplicidade, na sua organização é importante à medida que subsidia a compreensão sobre o lugar que the é atribuído na configuração da proteção social de uma sociedade, em determinado momento histórico. Particularmente, como ela é incorporada à política social, quais famílias são incorporadas e em quais políticas e os impactos que essas políticas tem na vida da famílias. Como afirma EspingAndersen a forma de gerir e distribuir os riscos sociais entre o Estado, o mercado e a família faz uma grande diferença nas condições de vida de uma população (EspingAndersen, 2000). Portanto para pensar em trabalho com famílias é importante reconhecer quais as tendências predominantes na incorporação da família no campo da política social enquanto seu sujeito destinatário. A grosso modo, temos indicado que atualmente existem duas grandes tendências em disputa nesse campo que vimos denominando de proposta familista e de proposta protetiva.

A idéia central da proposta familista reside na afirmação da tradição secular que existem dois canais naturais para satisfação das necessidades dos indivíduos: a família e o mercado. Somente quando esses falham é que interferência pública deve acontecer e, de maneira transitória. Então a idéia que vem embutida no campo da incorporação da família na política social é a idéia de falência da família. Ou seja, a política pública acontece prioritariamente, de forma compensatória e temporária, em decorrência da sua falência no provimento de condições materiais e imateriais de sobrevivência, de suporte 
afetivo e de socialização de seus membros. Isso corresponde a uma menor provisão de bem-estar por parte do Estado.

O fracasso das famílias é entendido como resultado da incapacidade de gerirem e otimizarem seus recursos, de desenvolverem adequadas estratégias de sobrevivência e de convivência, de mudar comportamentos e estilos de vida, de se articularem em redes de solidariedade e também de serem incapazes de se capacitarem para cumprir com as obrigações familiares.

Essa concepção foi delineada no âmago do desenvolvimento capitalista e do liberalismo econômico - século XVIII e IXX- quando, com a separação entre casa e empresa, se conformou uma nova forma de família (família nuclear burguesa). Nesse momento, foi delegado a ela a responsabilidade pela reprodução social e junto se jogou também para dentro delas os problemas e os conflitos gerados na esfera da produção. Afinal, a insuficiência de recursos para a provisão de bem-estar advindas, por exemplo, do desemprego, passou a ser tratado como "caso", ou, "problemas de família". Essa é, portanto, a concepção que se revitaliza no bojo do ideario neo-liberal, com a proposição do pluralismo de bem-estar social. Proposição que se realiza numa realidade onde se está cada vez mais distante da possibilidade da família contar com um manancial de recursos suficientes para responder às necessidades de seus membros e as expectativas que lhe são colocadas (MARTIN, 1995; MIOTO, 2004). Esta é uma questão crucial na análise da impossibilidade real dessa "revivência" da família como instância principal de proteção social.

A crítica mais contundente à afirmação da família como referência das políticas públicas, na atualidade, está associada à regressão da participação do Estado Social na provisão de bem-estar. Ou seja, desvia da rota da garantia dos direitos sociais através de políticas públicas de caráter universal e entra na rota da focalização das políticas públicas nos seguimentos mais pauperizados da população, fortalece significativamente o mercado enquanto instância de provisão de bem-estar e aposta na organização sociedade civil como provedora. Nessa configuração a família é chamada a reincorporar os riscos sociais e com isso assiste-se um retrocesso em termos de cidadania social.

Ao contrário, na proposta protetiva, persiste-se na afirmação que a proteção se efetiva através da garantia de direitos sociais universais, pois somente através deles é 
possível consolidar a cidadania e caminhar para a equidade e a justiça social. De acordo com Esping-Andersen, pode-se dizer que a cidadania social vincula-se a dois processos: ao processo de desmercadorização- que consiste na possibilidade que o indivíduo e a família têm de se manter sem depender do mercado-; e ao processo de "desfamilização". Desfamilização, significa o abrandamento da responsabilidade familiar em relação a provisão de bem estar social, seja através do Estado ou do mercado. Como afirma Chiara Saraceno (1996), a presença do Estado na garantia dos direitos sociais torna possível a autonomia dos indivíduos em relação à autoridade familiar e da família em relação à parentela e a comunidade. Pressupõe a diminuição dos encargos familiares e a independência da família especialmente em relação ao parentesco. Nessa perspectiva as políticas públicas são pensadas no sentido de "socializar antecipadamente os custos enfrentados pela família, sem esperar que a sua capacidade se esgote". Essa concepção tem uma conseqüência importante para o exercício profissional, pois há o deslocamento do eixo da busca das causas dos problemas e conflitos, numa análise predominantemente relacional, e se caminha para o fortalecimento das possibilidades de proteção das famílias. Esse processo compartilhado com as famílias desemboca na construção de sua autonomia enquanto sujeitos e portanto não são tratadas como objetos terapêuticos.

Essa diferenciação entre propostas nos dá a clara medida do tensionamento de projetos no campo da política social. Tal tensionamento acontece desde o plano da formulação da política até seu processo de implantação e execução. Portanto, as ações profissionais desenvolvidas no âmbito das políticas sociais expressam tanto uma concepção de família como de suas relações no campo social. Isso significa dizer que o como os profissionais desenvolvem suas ações torna-se uma questão fundamental na afirmação de projetos profissionais e societários.

\section{O trabalho com famílias: algumas indicações para afirmação da proposta protetiva}

Tendo em conta as referências apresentadas e retomando a idéia das possibilidades que o paradigma crítico-dialético abriu para o redimensionamento da ação 
profissional é necessário demarcar esse redimensionamento no campo do trabalho com famílias. Nesse sentido se faz necessário reafirmar como as demandas das famílias são interpretadas e qual direcionalidade é dada para o atendimento de tais demandas pelos assistentes sociais, através de seu processo de trabalho.

Em relação a interpretação da demanda, a sua compreensão parte da idéia que as demandas são expressões de necessidades, decorrentes especialmente da desigualdade social própria da organização capitalista.e portanto, não podem ser mais tomados como problemas de família. Assim, o assistente social passa a desvincular a satisfação das necessidades sociais à competência ou incompetência individual/das famílias. Ou seja, compreendendo os processos familiares como uma construção singular, arquitetada na família, no entrecruzamento das múltiplas relações, que condicionam e definem a dinâmica familiar. Essa compreensão de processos familiares permite em primeiro lugar desvincular-se da idéia de uma dinâmica familiar reduzida à compreensão das relações de afeto e cuidado no interior da família. Ou seja, o desafio é buscar como essa dinâmica é definida pela multiplicidade de fatores que incide sobre ela e, portanto, exige uma análise aprofundada entre a estrutura de proteção que as famílias apresentam e a estrutura necessária para que elas possam fazer frente às suas necessidades nos diferentes momentos e situações de vida. Adota-se como carro chefe para o conhecimento das famílias, a categoria das necessidades humanas e a sua estrutura de cuidado e proteção, ao invés do inventário e história de seus problemas e dificuldades. Enfim, entende que a responsabilidade da proteção social não está restrita às famílias e, portanto, a solução dos mesmos extrapola as suas possibilidades individuais. Condiciona a proteção social, exercida pela família, ao acesso à renda e ao usufruto de bens e serviços de caráter universal e de qualidade.

No tocante a direcionalidade da ação profissional, como já foi afirmado, há a exigência que ela seja pensada na sua teleologia. Para além de sua eficiência operativa ou de sua instrumentalidade. Portanto, há necessidade de incorporar a ela o compromisso ético com a transformação social, que nesse contexto sócio-histórico se traduz em conquista e garantia de direitos. Essa perspectiva implica que, ao reconhecer que as famílias apresentam demandas que extrapolam as suas possibilidades de repostas e essas se encontram também fora delas, a ação profissional não pode direcionar-se apenas as 
famílias enquanto sujeitos singulares. Isso implica no redimensionamento da intervenção profissional, a partir da perspectiva da integralidade das ações articuladas em diferentes níveis. Esses níveis seriam: proposição, articulação e avaliação de políticas sociais, organização e a articulação de serviços e atendimento a situações singulares (MIOTO, 2000).

A avaliação e proposição de políticas públicas consiste em estabelecer mecanismos de sistematização e estudo de informações sobre as famílias em, basicamente, dois aspectos. $O$ primeiro vincula-se às necessidades das famílias que podem ser identificadas nas unidades de serviços, através das demandas de seus usuários. O segundo, sobre elementos que possam subsidiar a avaliação dos impactos que as políticas públicas têm no cotidiano da vida das famílias. Esse conhecimento é que torna possível, não só a avaliação das políticas, mas também o encaminhamento de proposições, através de ações coletivas e de controle social.

A organização e a articulação de serviços é um aspecto fundamental para atender as necessidades das famílias e garantir eficazmente uma estrutura de cuidado e proteção. Isso só se torna possível quando a organização dos serviços é estruturada de forma a permitir e facilitar o acesso das famílias. Recobre um arco bastante grande de questões, que vai desde os horários de funcionamento dos serviços até os níveis de exigências direcionados às famílias. A avaliação dessas exigências é fundamental para que o serviço não se transforme também em mais uma fonte de estresse para as famílias. Para tanto, a criação de espaços de gestão democrática, com participação das famílias enquanto sujeitos de direitos, torna-se um mecanismo necessário, interessante e salutar. 0 atendimento de famílias em situações singulares refere-se ao trabalho desenvolvido diretamente com as famílias. Acontece, através de um processo compartilhado entre famílias e profissionais mediante o qual a autonomia das famílias se constrói, se reconstrói e se preserva. De forma geral, o objetivo principal é identificar as fontes de dificuldades familiares, as suas possibilidades de mudanças e os recursos necessários para que as famílias consigam articular respostas compatíveis com uma melhor qualidade de vida. Tais mudanças pressupõem transformações tanto nos padrões de relações internas da família, como dos padrões de relações entre ela e as outras esferas da sociedade. Isto implica no desenvolvimento da capacidade de discernir as mudanças possíveis de serem 
realizadas no âmbito dos grupos familiares e de suas redes, daquelas que exigem o engajamento em processos sociais mais amplos para que ocorram transformações de ordem estrutural.

A articulação nesses diferentes níveis requer o encaminhamento de diferentes ações profissionais que se estruturam em três grandes processos: processos políticoorganizativos, processos de gestão e planejamento e processos sócio-assistenciais (MIOTO; NOGUEIRA, 2006; MIOTO; LIMA, 2009). Resumidamente, os processos políticoorganizativos no trabalho com famílias implicam em ações que privilegiem e incrementem a discussão da relação família e proteção social na esfera pública, visando o rompimento com a ideologia vigente da família como responsável da proteção social, buscando a garantia e ampliação dos direitos sociais. Ações que considerem não só as necessidades imediatas, mas prospectam, a médio e a longo prazos, a construção de novos padrões de sociabilidade entre os sujeitos. As ações nesse âmbito possuem caráter coletivo e dentre elas destacam-se as de assessoria e mobilização junto às famílias, aos conselhos de direitos e aos movimentos sociais organizados. Os processos de planejamento e gestão vinculam o conjunto de ações profissionais desenvolvidas com enfoque no planejamento institucional como instrumento de gestão e gerência de políticas e serviços. Buscam o deslocamento do foco do atendimento dos objetivos institucionais para o atendimento das necessidades das famílias. Nesse sentido é fundamental a interferência no sentido de construir práticas efetivas de intersetorialidade, ou de gerir as relações interinstitucionais na busca de aliviar a carga de trabalho impingida pelos serviços às famílias. Ou seja, para reverter o processo de responsabilização da família pelo cuidado, prática tão naturalizada no âmbito de equipes multidisciplinares. Finalmente os processos sócio-assistenciais correspondem as ações profissionais desenvolvidas diretamente com as famílias. Sua lógica reside em atendê-las enquanto sujeitos e não como objetos terapêuticos. Assim, busca-se responder às suas demandas/necessidades numa perspectiva de construção da autonomia. Autonomia que Ihes permitam um engajamento ativo no contexto da participação política.

Partindo dessas indicações para o trabalho com famílias é que se torna possível a construção de metodologias de trabalho. Metodologias entendidas como opções realizadas pelos profissionais por determinadas formas de condução das ações 
profissionais em determinado momento tendo em vista a efetivação de determinados objetivos e finalidades. Portanto elas não podem ser construídas à priori, mas no processo. Enfim, uma construção que depende da definição dos fundamentos teóricometodológicos e ético-políticos que sustentam as ações profissionais, das finalidades que orientam tal ação, além do conhecimento/investigação necessários sobre o objeto da ação e dos objetivos que se quer alcançar. São estas definições que vão orientar e exigir outras definições tais como os sujeitos destinatários das ações, as formas de abordagem, os instrumentos técnico-operativos, bem como os recursos necessários. Portanto, todo esse processo não acontece de forma aleatória, mas de forma planejada e ancorada numa documentação que alimenta o próprio processo. Como afirma Campos $(2008,117)$, ao discutir metodologia do trabalho social, a consistência interna das metodologias de trabalho profissional exigem: “a) seu teste operativo, configurado na capacidade traduzir em atos e posturas os conceitos e objetivos que postula. b) sua resposta definida, adaptada ao tempo e ao espaço em que se desenvolve, condicionantes de sua configuração. c) sua precisão quanto aqueles que busca atingir e à participação deles no desenvolvimento do caminho metodológico. d) sua previsão de recursos de todas as ordens, existentes e disponíveis em determinados prazos; incluem-se aí as pessoas que desenvolvem ações pautadas numa metodologia. e) seu sistema de controle das informações, monitoramento e avaliação."

Concluindo, quero enfatizar que a discussão e a indicações propostas devem ser entendidas como contribuições para o debate. Para um debate que precisa ser fortalecido e aprofundado para que se possa construir um campo estruturado de conhecimento,. que permita sustentar o exercício profissional dos assistentes sociais com famílias numa lógica protetiva e que, de fato, possa materializar o projeto ético-político do Serviço Social.

\section{Referências}

CAMPOS, M. S. As metodologias e seus componentes: conferência, metodologias do trabalho social. São Paulo: IEE/PUC-SP, 2008. p. 113-129.

ESPING-ANDERSEN, G. Fundamentos sociales de las economías postindustriales. Barcelona: Ariel, 2000. 
GUERRA, Y. Instrumentalidade do processo de trabalho e Serviço Social. Serviço Social e Sociedad, São Paulo, n. 62, 2000.

HAMILTON, G. Teoria e prática do serviço social de caso. 3. ed. Rio de Janeiro: Agir, 1976.

IAMAMOTO, M. Renovação e Conservadorismo no Serviço Social: ensaios críticos. 2. ed. São Paulo: Cortez, 1994.

IAMAMOTO, M.; CARVALHO, R. Relações sociais e serviço social no Brasil: esboço de uma interpretação histórico-metodológica. São Paulo: Cortez, 1983.

LIMA, T.C.S., MIOTO,R.C.T. Direitos, cidadania e necessidades humanas básicas: conceitos imprescindíveis no debate da proteção social. Sociedade em Debate, Pelotas, v.12,n.1, 2006, p.29-49.

MARTIN, C. Les fonctions de la famille. Cahiers Français. França: La Documentación Française, set/out. 1995, n.322.

MIOTO, R. C. T.; NOGUEIRA, V. M. R. Sistematização, planejamento e avaliação das ações dos assistentes sociais no campo da saúde. MOTA, A. E. et al. (Org.). Serviço social e saúde: formação e trabalho profissional. São Paulo: Cortez, 2006. p. 273-303.

MIOTO, R.C.T.; LIMA, T.C.S. A dimensão técnico-operativa do Serviço Social em foco: sistematização de um processo investigativo. Textos \& Contextos, Porto Alegre, v. 8, n.1, p. 22-48, jan./jun. 2009.

- Cuidados sociais dirigidos à família e segmentos sociais vulneráveis. UNIVERSIDADE DE BRASÍLIA. Cadernos capacitação em serviço social e política social,. Brasília: CEAD, 2000. mod. 4

NICHOLDS, E. Noções básicas de serviço social de caso. 2. ed. Rio de Janeiro.São Paulo: Cortez, 1969

PEREIRA, P. A. P. Mudanças estruturais, política social e papel da família: crítica ao pluralismo de bem-estar. In: direitos. São Paulo: Cortez, 2004. p. 25-42.

SARACENO, C. Sociologia della Famiglia. Bologna: II Mulino, 1996.

VIEIRA, E. Os Direitos e a política social. São Paulo: Cortez, 2004.

YASBEK, M. C. Classes subalternas e assistência social. São Paulo: Cortez, 1993. 